\title{
Dopaminergic involvement in activational aspects of motivation: Effects of haloperidol on schedule-induced activity, feeding, and foraging in rats
}

\author{
JOHN D. SALAMONE \\ Emory University, Atlanta, Georgia
}

\begin{abstract}
The dopamine antagonist haloperidol (HP) decreased motor activity that was induced by periodic presentation of food to food-deprived rats, with the higher doses leading to a marked decline in activity across the 30 -min test session. However, HP-treated rats continued to consume all the food pellets, and 1 rat that was directly observed continued to remain in proximity to the food dish. HP also disrupted foraging and food intake in a seminaturalistic environment. In addition to decreasing food intake, HP decreased the average duration, and increased the total number, of feeding bouts. These results indicate that although HP disrupted the activational aspects of food-motivated behavior in these tasks, HP-treated subjects continued to direct behavior toward food acquisition and consumption.
\end{abstract}

Administration of dopamine (DA) antagonists to animals or humans suppresses a wide variety of behaviors. Although this observation is hardly debatable, the precise reasons for the response-suppressing effects of these drugs are still in dispute. It has been suggested that DA antagonists cause impairments in the initiation of movement or the execution of motor acts (Ahlenius 1979; Fibiger, Carter, \& Phillips, 1976; Rolls et al., 1974). Such deficits are hypothesized to lead to a decrease in the performance of, for example, "spontaneous" activities and appetitive and aversive instrumental behaviors (Fibiger et al., 1976; Janssen, Niemegeers, \& Schellekens, 1965; Rolls et al., 1974). These motor hypotheses are consistent with the debilitating motor effects that result from lesions of brain DA systems (Marshall, Richards, \& Teitelbaum, 1974; Stricker \& Zigmond, 1976; Ungerstedt, 1971) and the involvement of brain DA in the motor disorder Parkinson's disease (see review by Hornykiewicz, 1972).

It also has been suggested that appetitive instrumental behaviors are suppressed by DA antagonists because these drugs reduce the rewarding impact of such stimuli as food, water, and electrical brain stimulation (Wise, 1982; Wise, Spindler, DeWitt, \& Gerber, 1978; Wise, Spindler, \& Legault, 1978). Early evidence in support of this view came from studies showing that DA antagonists produced a decline in responding over time that is similar to extinction on some schedules of reinforcement (Wise, Spindler, DeWitt, \& Gerber, 1978; Wise, Spindler, \& Legault, 1978). More recently, Wise $(1982,1985$; Gray \& Wise, 1980 ) extended his hypothesis to propose that dopamine

Thanks are extended to D. B. Neill for his helpful comments. Reprint requests may be sent to the author at the Department of Psychology, University of Connecticut, Storrs, CT 06268. antagonists produce a motivational deficit, or an attenuation of "motivational arousal." These hypothesized deficits in reinforcement and motivational processes have been described as being distinct from the motor effects of DA antagonists (Wise, 1982, 1985).

In a recent review, Salamone (1987) suggested that a motivational interpretation of DA-antagonist effects should not be considered as incompatible with the motor functions traditionally assigned to DA systems. A number of researchers have noted that motor activity is an important feature of motivated behavior. Stricker and Zigmond (1976) acknowledged the relationship between motor activity and motivation, and observed that lesions of brain DA systems reduced "behavioral responsiveness" (p. 140). Broekkamp, Van Dangen, and Van Rossum (1977) argued that it was somewhat arbitrary to draw a line between motivational and motor systems in the brain. Young (1961) observed that the arousal of activity, the sustaining of activity in time, and the regulation of the pattern of activity are processes fundamentally related to the concept of motivation.

The present experiments were conducted to illustrate that the DA antagonist haloperidol (HP) produces deficits in aspects of motor output that are necessary for the performance of food-motivated behaviors. In Experiment 1, the effects of HP on motor activity induced by periodic presentation of food were assessed. Killeen $(1975,1981)$ showed that food-deprived animals that received scheduled presentations of single food pellets exhibited increased motor activity directly related to the rate of food presentation. This paradigm offers a way of studying the effects of HP on the arousal of activity induced by a motivationally relevant stimulus. In Experiment 2, HP was administered to rats trained on a foraging paradigm in which complex and highly organized food-related be- 
haviors were observed. The results of these experiments allowed for the assessment of the effects of HP on the arousal, maintenance, and pattern of food-motivated behaviors.

\section{EXPERIMENT 1}

In Experiment 1, HP was administered to animals trained on a schedule-induced activity paradigm. Initially, the relationship between the rate of food presentation and the number of motor activity counts was investigated in order to establish that the activity observed in the apparatus was food-related, and to select a rate of food delivery that was suitable for the HP study. Next, a group of rats was used to study the effects of HP on schedule-induced motor activity. Finally, 1 of the subjects in the drug study was directly observed in the activity chamber in order to record the time it spent in proximity to the food dish; the effects of HP on this behavior were compared with those of extinction.

\section{Method}

Subjects. Male Sprague-Dawley rats (Harland, Madison, WI), which weighed $350-400 \mathrm{~g}$, were used. Each rat was individually housed in a colony with a temperature of $22^{\circ}-2^{\circ} \mathrm{C}$ and a $12-\mathrm{h}$ light:dark cycle (lights on at $0800 \mathrm{~h}$ ). All rats were deprived to $85 \%$ of their free-feeding body weights. One rat was used to investigate the relationship between rate of food presentation and activity. Six rats were used for the drug study, and 1 of them was directly observed with respect to its proximity to the food dish, as described below.

Apparatus. The activity box was a rectangular, $52 \times 33 \times 33 \mathrm{~cm}$, wooden box. The floor consisted of three rectangular, $16 \times 28 \mathrm{~cm}$ panels. Each panel was balanced on a rod in the center, and thus could be displaced slightly up and down. When a given side of a panel was displaced, the lever on that side triggered a microswitch on the outside of the box. The pulsed output of each switch triggering was counted as a single activity count. In the middle of one side of the box was an $8 \times 5 \mathrm{~cm}$ aluminum food dish. A Davis Instruments feeder delivered 45-mg Bioserve food pellets to the food dish. Electromechanical counters and timers were used to control the experiment and collect activity data. A small wide-angle viewing port in the chamber wall enabled an observer to record behavioral data without disturbing the rat.

Procedure. All sessions were $30 \mathrm{~min}$, and were conducted in the period 2-8 h after lights on. An individual rat was used to study the effect of food delivery rate on activity. This rat was initially exposed to a schedule of receiving one $45-\mathrm{mg}$ food pellet every $30 \mathrm{sec}$ (fixed time, or FT, $30 \mathrm{sec}$ ). After several days of initial exposure, the rat then received two 3-day blocks under each of the following schedules: FT $30 \mathrm{sec}$, FT $60 \mathrm{sec}$, FT $120 \mathrm{sec}$, FT $360 \mathrm{sec}$, and extinction. The particular order in which the 3day blocks were conducted was randomly varied.

The 6 rats used to study the effects of HP on schedule-induced activity were all tested on an FT $30-\mathrm{sec}$ schedule. The rats were exposed to the schedule in the activity chamber for several days, until the number of activity counts was relatively stable. Predrug baseline data were then gathered. A rat was considered to have stable baseline performance if, over 3 consecutive days, the total number of activity counts for each day did not vary by more than $25 \%$ from the mean of all 3 days. Reaching the baseline criterion led to a treatment day, which was followed by a rest day. This sequence of baseline/treatment/rest was repeated until each rat had received all four treatments in random order. The treatments were $1.0 \mathrm{ml} / \mathrm{kg}$ physio- logical saline and $0.1,0.2$, and $0.4 \mathrm{mg} / \mathrm{kg} \mathrm{Haldol} \mathrm{(McNeill} \mathrm{Labora-}$ tories), all delivered i.p. $60 \mathrm{~min}$ before testing began.

For 1 rat, an observer, who was unaware of the particular experimental conditions, recorded the time that the rat spent in proximity to the food dish. This was defined as any time in which the rat was facing the food dish within one headlength of its edge. The observations on this rat were made during the sessions in which the rat received 0.2 and $0.4 \mathrm{mg} / \mathrm{kg} \mathrm{HP}$, and also on the baseline days prior to each of these two treatments. After receiving the treatments for the drug study, this rat was tested and observed during extinction. In this particular extinction procedure, the feeder was operated every $30 \mathrm{sec}$, but no food was delivered.

Data analysis. Total activity counts for the treatment days were calculated as a percent of the mean of the 3 previous baseline days. These data were analyzed by a repeated measures analysis of variance (ANOVA). Activity data were also recorded within the five 6-min periods over the 30-min session. For the data across the 30 min session, each individual dose was analyzed by a repeated measures ANOVA.

\section{Results}

Effect of food-presentation rate. Figure 1 shows the relationship between rate of food presentation and activity counts obtained from an individual rat. Activity for this animal increased in a monotonic, negatively accelerated fashion with increasing rate of food presentation. Activity was lowest under extinction. These data are consistent with the notion that the activity observed was scheduleinduced, and not merely a result of food deprivation.

Treatment effects. HP administration reduced overall activity in a dose-related manner. Figure 2a shows the dose-response curve for total activity in the session. The main treatment effect was significant $[F(3,15)=20.32$, $p<.01]$. Figure $2 \mathrm{~b}$ displays the data on activity across the session within the five 6-min periods. There was no significant overall decline in activity across the session under saline or $0.1 \mathrm{mg} / \mathrm{kg}$ HP. However, there were significant declines after administration of $0.2 \mathrm{mg} / \mathrm{kg}$ $[F(4,20)=15.44, p<.01]$ and $0.4 \mathrm{mg} / \mathrm{kg} \mathrm{HP}[F(4,20)$ $=20.39, p<.01]$.

Despite the decrease in activity that was produced by HP, all rats ate all 60 of the pellets delivered. The results of the observations of proximity to the food dish are shown in Figure 3. On the baseline day, the rat spent a considerable amount of time near the food dish; this behavior was sustained throughout the test session. On the days that the rat had received 0.2 or $0.4 \mathrm{mg} / \mathrm{kg} \mathrm{HP}$, the rat continued to stay in proximity to the food dish and consumed all of the food pellets. However, under extinction, the behavior of being in proximity to the food dish declined over the course of the session.

\section{Discussion}

Administration of HP led to a dose-related suppression of schedule-induced activity. HP decreased the total amount of activity and led to a decline in responding across the test session. Despite the reduction in motor activity, all HP-treated rats consumed the food pellets that were presented. The data from the rat observed for proximity to the food dish indicate that, even though HP reduced 


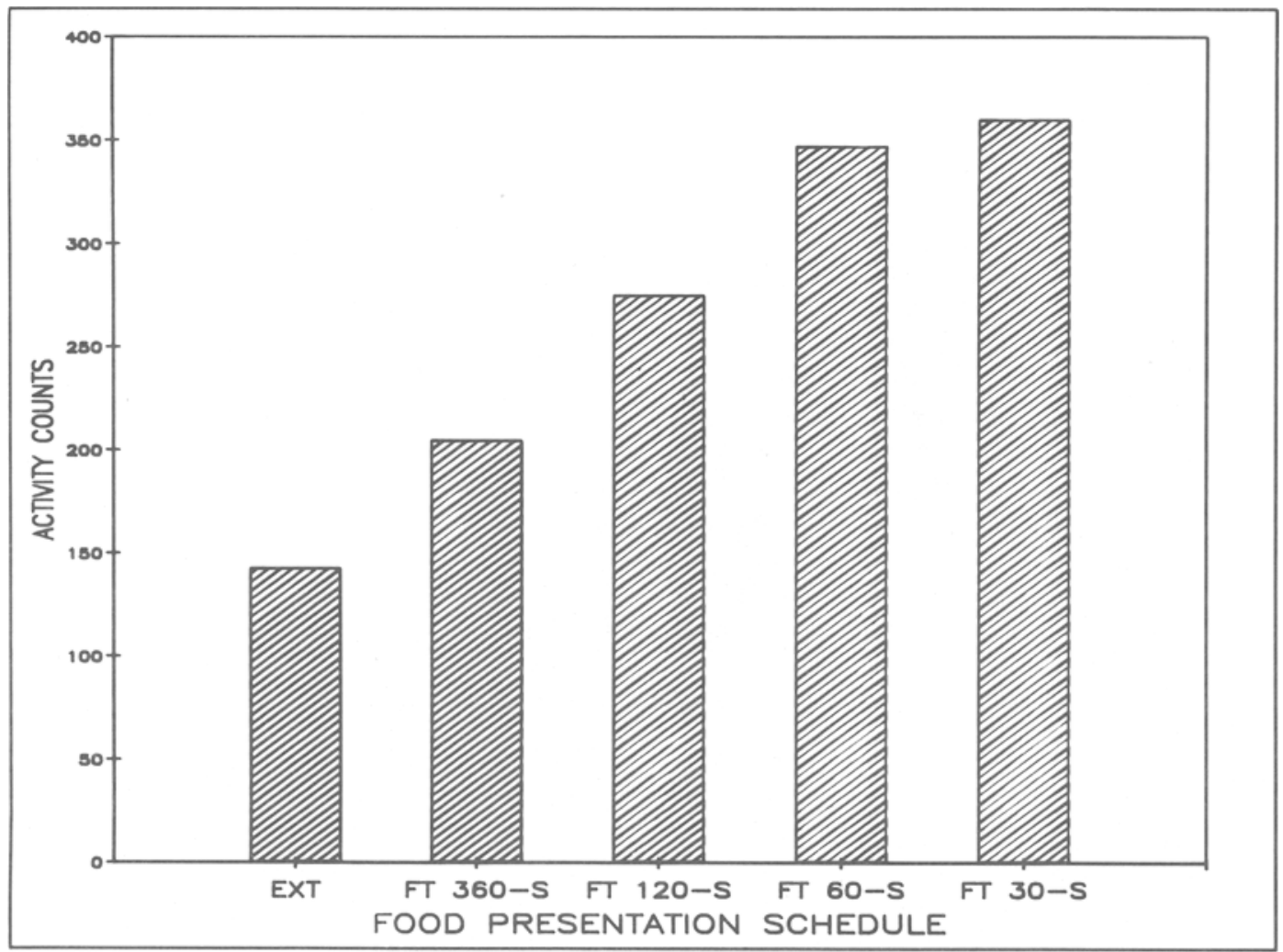

Figure 1. Activity counts obtained from the individual rat exposed to various schedules of food presentation.

the motor activity induced by food presentation, the HPtreated animal continued to direct its behavior toward the food dish and engage in food consumption.

The present results are consistent with previous reports of a disruption of schedule-induced behavior by injection of DA antagonists or by lesions of brain DA systems (Keehn, Coulson, \& Klieb, 1976; Keehn \& Riusech, 1977; Robbins \& Koob, 1980; Wallace, Singer, Finlay, \& Gibson, 1983). Periodic presentation of food to fooddeprived rats was also shown to increase striatal DA release and metabolism (Church, Justice, \& Neill, 1987; Salamone, Abercrombie, Keller, Zigmond, \& Stricker, 1987). Taken together, these results indicate an important role for DA in the regulation of motor activity induced by periodic food presentation.

\section{EXPERIMENT 2}

The purpose of Experiment 2 was to investigate the effects of DA antagonism on feeding and foraging in a complex seminaturalistic environment. Such an environment led to the development of highly organized food-searching and feeding behaviors. Thus, this study offered a way to assess the effects of HP on the patterning and organization of motor output during food-motivated behavior.

\section{Method}

Subjects. Six male albino rats were obtained from the same source and housed and deprived under the conditions as described above.

Apparatus. The rats were tested in a large room measuring $4.6 \times 2.3 \mathrm{~m}$. The test-room floor is depicted in Figure 4. Food pellets in the foraging room were Purina Laboratory Rat Chow pellets cut to a weight of $1.5 \mathrm{~g}$. In the room were three sets of possible food locations: along the wall, next to blocks in the middle of the floor, or on top of platforms along the wall. Each set had four possible loci. Two $1.5 \mathrm{-g}$ pellets were randomly distributed to each of the three sets of locations, so that six pellets $(9.0 \mathrm{~g}$ total) were scattered on the floor. An observer recorded behavioral events by triggering switches on a panel that was connected to electromechanical counters, timers, and an event recorder.

Procedure. Testing in the foraging room was initiated by placing the food-deprived rat, in its home cage, on the floor of the room, as shown in Figure 4. This was done for several days, and the rat quickly learned to leave the home cage within 1-10 sec and to pick up the first food pellet within $10-20 \mathrm{sec}$. When it appeared that the behavior of the rat in leaving its cage, finding the food, and consuming it was relatively stable, initial baseline data were gathered. Baseline data did not change consistently over the entire course of Experiment 2.

All baseline and treatment tests were conducted during the light part of the light:dark cycle $2-8 \mathrm{~h}$ after light onset. During the $30-\mathrm{min}$ session, an observer recorded the following behaviors: latency to first leave the home cage, numbers of returns to the home cage, approaches to a possible food locus along the wall, approaches to a block in the center, approaches to a platform, and platform climbs, 

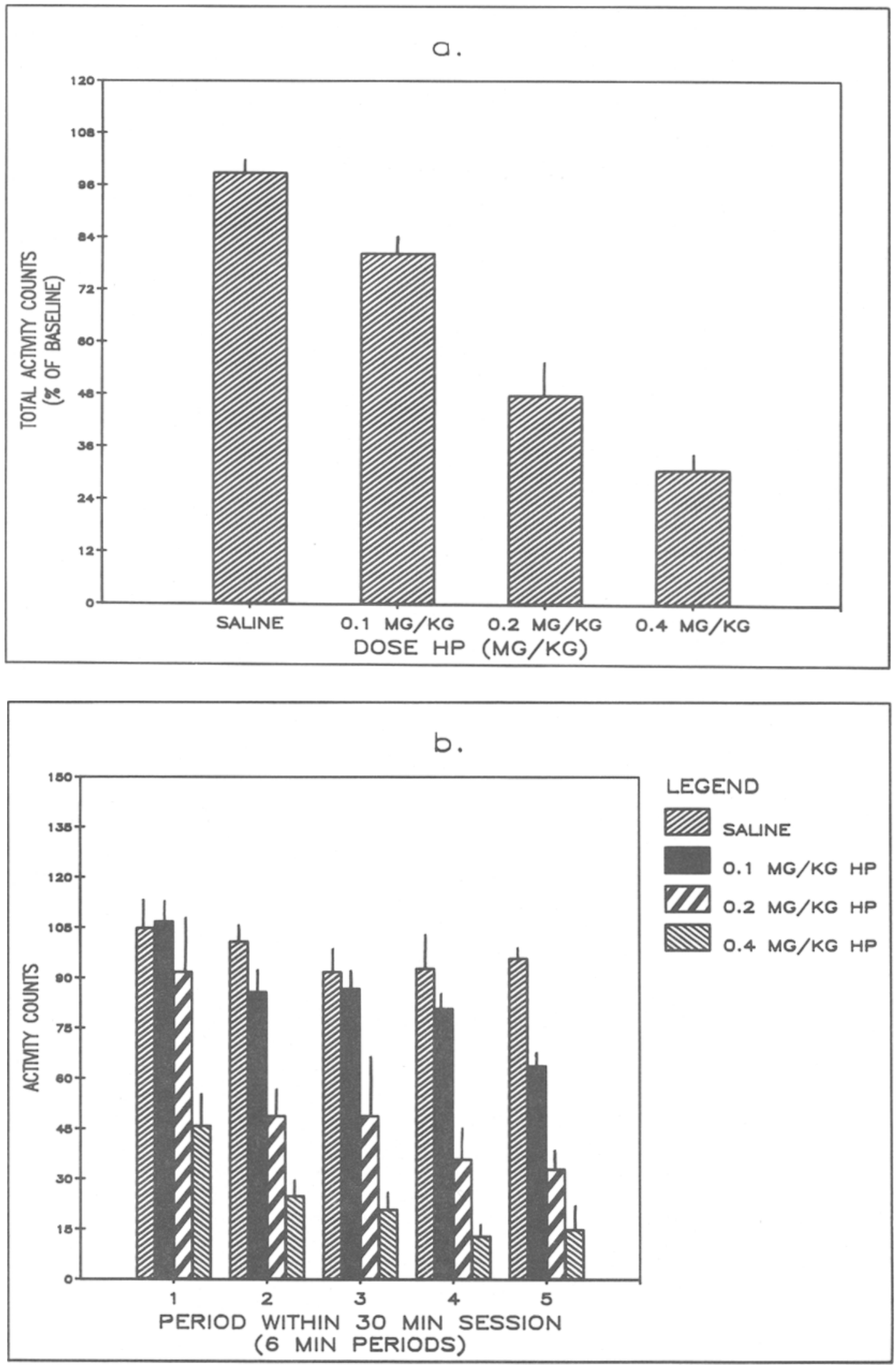

Figure 2. (a) Mean (+SEM) activity counts (as a percent of baseline) for all treatment conditions. (b) Mean ( $+S E M)$ activity counts for all conditions within the five 6-min periods of the 30 -min session. 


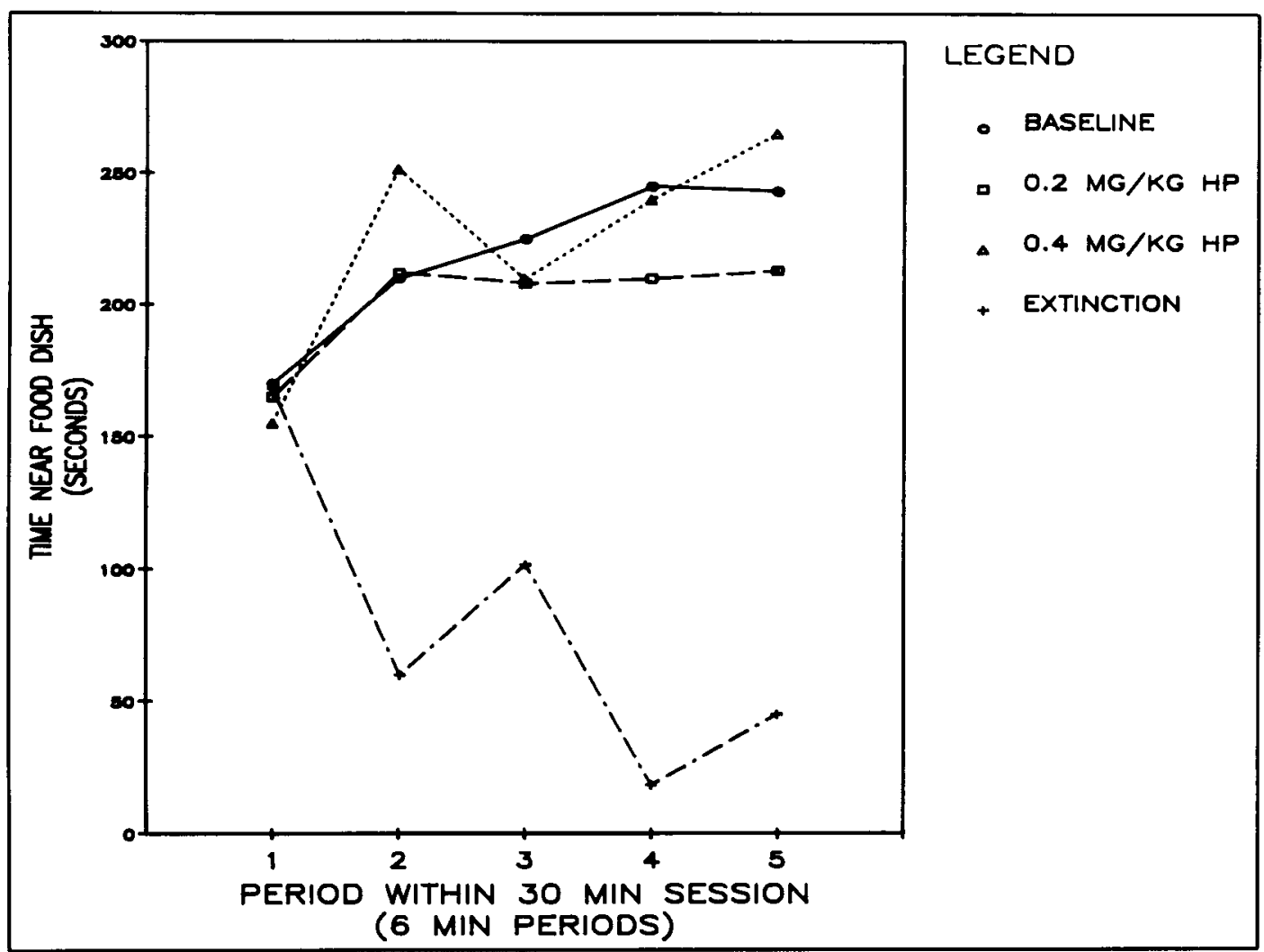

Figure 3. Time spent in proximity to the food dish (across the five 6-min periods of the session) for the individual rat that was observed during baseline, 0.2 and $0.4 \mathrm{mg} / \mathrm{kg}$ HP, and extinction.

and latencies to pick up each pellet. An approach to a wall or a middle locus was defined as the rat's placing its head over the block of wood or inside the space marked by the rectangular floor markings surrounding that locus. An approach to a platform was defined as the rat's rearing with its head in proximity to the side of the platform. A climb was recorded when the rat's entire body was on top of the platform. A pickup was recorded when a pellet the rat had picked up from the floor was actually in the rat's mouth.

In addition to the behaviors mentioned above, the experimenter counted locomotor activity (defined as the rat's crossing over, with its entire body, one of the floor markings shown in Figure 4) and feeding behavior. Feeding was defined as any time the rat was directly chewing on a food pellet or continuing a sequence of chewing that had been initiated with contact to a food pellet. Each locus in the test room where the animal ate during a given session was recorded. Food not eaten by the animal was weighed (to $0.1 \mathrm{~g}$ ) after the session to calculate the quantity of food intake. The observer also noted the number of partially eaten pellets removed.

A rat was considered to have a stable baseline if it had 3 consecutive baseline days, during which the amount of food consumed each day was not more than $25 \%$ different from the mean of all 3 days. As with the drug experiments described above, each rat was exposed to the sequence of baseline/treatment/rest until it had completed all 4 treatment days in random order. Treatments were $1.0 \mathrm{ml} / \mathrm{kg}$ saline and $0.1,0.2$, and $0.4 \mathrm{mg} / \mathrm{kg} \mathrm{HP}$ given i.p. $1 \mathrm{~h}$ before testing began. The observer was unaware of the treatment condition.

Data analysis. Data for most behaviors observed were calculated as a percentage of the previous mean baseline for that behavior.
The number of loci where food was eaten was expressed in terms of a change from baseline rather than as a percentage. Event records were used to calculate the number of bouts of feeding (defined as a period of at least $5 \mathrm{sec}$ of feeding preceded and followed by at least $5 \mathrm{sec}$ of no feeding), and the duration of each bout. The proportion of interbout intervals that contained some other behavior (any of those described) was calculated, as was the total time spent between feeding bouts. The latency to pick up the first pellet was recorded, and the average interval between pickups was computed. The appropriate data were analyzed with repeated measures ANOVAs, and post hoc comparisons between the effects of doses of HP and saline were performed with the Dunnett's test ( $\alpha=$ .05 ). The sign test was used for instances in which the saline data were not distributed normally, because the behaviors in question rarely occurred under saline (e.g., leaving partially eaten pellets and feeding in bouts 5-60 sec in duration).

\section{Results}

Description of foraging and feeding behavior. Because this was a novel behavioral paradigm, the normal pattern of behavior that emerged on baseline and saline days should be described. Typically, the rat would locate and pick up a single pellet, take the pellet to a specific feeding locus, and consume the pellet completely in one feeding bout. The mean probability of a pickup's being followed by a feeding bout (as opposed to a second pickup) on saline days was $.86( \pm 0.05)$. Each animal had idiosyn- 


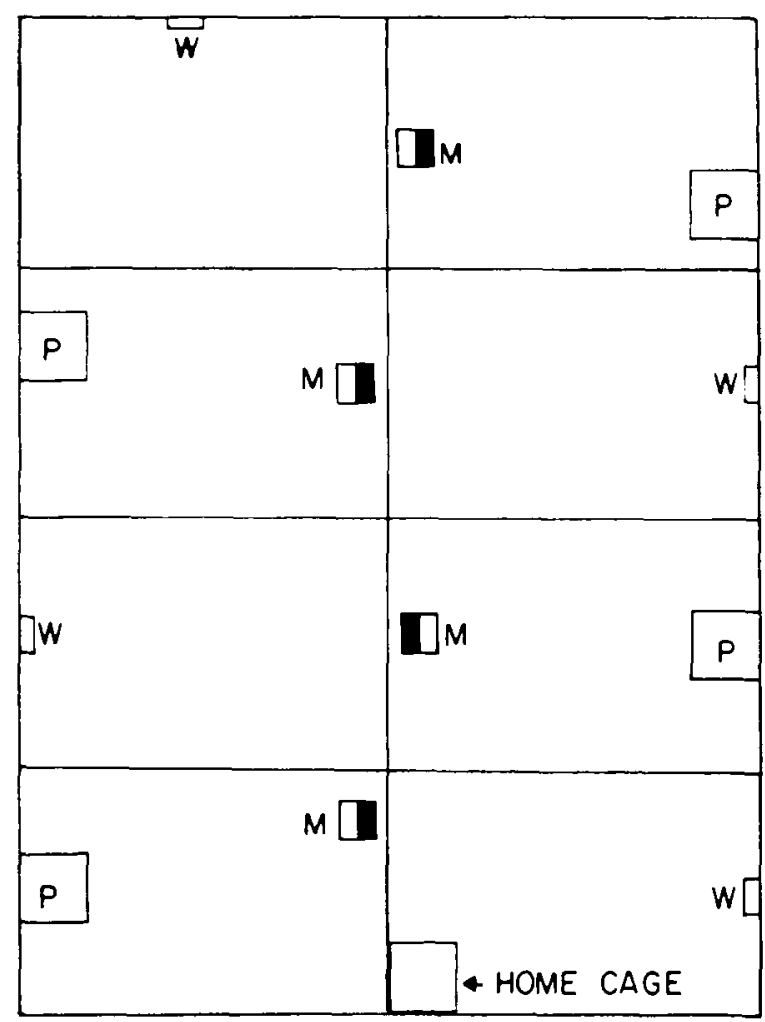

Figure 4. A representation of the floor of the foraging test room. $W=$ possible wall loci for food, $P=$ possible platform loci for food, and $\mathbf{M}=$ possible middle loci for food.

cratic feeding loci, usually three to four in number. Although the specific feeding loci varied from animal to animal, all loci for all animals on baseline and saline days were either in corners (corners between the walls of the room, or corners between platforms and the wall) or in the rat's home cage. The rats would almost always consume entire pellets. Only once during a baseline test did a rat leave a partially eaten pellet, and that was because the session ended while the rat was still feeding. Across all baseline days, each rat usually ate five or six pellets (mean baseline food intake was $8.4 \pm 0.4 \mathrm{~g}$ ). In addition, the rats would alternate bouts of feeding with such activities as locomotion and approaches to or climbing upon food loci that did not contain food.

Treatment effects. Food intake in the foraging room was suppressed by HP. Figure 5a depicts food intake (as a percent of baseline) for all conditions. The overall treatment effect on food intake was significant $[F(3,15)=$ $20.4, p<.01]$, and there was a significant difference between saline and $0.4 \mathrm{mg} / \mathrm{kg} \mathrm{HP}$. Time spent feeding is displayed in Figure $5 \mathrm{~b}$ as a percent of baseline. HP also had a significant effect upon this feeding parameter $[F(3,15)=9.67, p<.05]$, with only the $0.4-\mathrm{mg} / \mathrm{kg}$ treatment differing from saline.

There were no significant effects of HP on locomotor counts, average interval between pickups, or number of pellets picked up. Table 1 shows the effects of HP on some additional behavioral measures. HP did not significantly affect latencies to leave the home cage or pick up the first pellet. There was a significant effect of HP on total approaches to middle food loci $[F(3,15)=18.0$. $p<.01]$ and on total approaches to platforms $[F(3.15)$ $=4.25, p<.05]$. Climbing on the platforms was significantly suppressed by HP treatment $[F(3,15)=3.49$. $p<.05]$. The number of feeding bouts increased across treatments $[F(3,15)=6.3, p<.01]$. Sign test comparison between saline and $0.4-\mathrm{mg} / \mathrm{kg}$ data revealed an increase in the number of partially eaten pellets $(p<.05)$. There was also an increase in the number of feeding loci across treatments $[F(3,15)=6.77, p<.01]$.

Figure $6 \mathrm{a}$ shows that the average duration of a bout of feeding decreased with HP treatment $[F(3,15)=21.0$, $p<.01]$. In Figure 6b, the duration of feeding bouts is broken down into the number of bouts that had 5-60-sec duration as compared with the number of bouts that had a duration greater than $60 \mathrm{sec}$. Over the HP doses used, there was an overall decrease in the number of bouts that were more than $60 \mathrm{sec}$ long $[F(3,15)=10.43, p<.01]$. Sign test analysis revealed that, relative to saline, there was a significant increase in the number of 5-60-sec bouts at both 0.2 and $0.4 \mathrm{mg} / \mathrm{kg} \mathrm{HP}(p<.05)$.

\section{Discussion}

Administration of HP resulted in a dose-related suppression and disorganization of behaviors in the foraging test. HP decreased total time spent feeding, amount of food intake, number of approaches to middle food loci and platforms, and number of platform climbs. These data are consistent with the notion that HP induces a hypokinetic state that leads to the suppression of a number of behaviors. However, note that, as well as decreasing the output of some behaviors, HP led to disorganized and fragmented responses, manifested in some cases as increases in the frequency of some behaviors. The rats no longer finished pellets sequentially, but instead left partially eaten pellets to begin eating other pellets. Many of the rats broke from the pattern of feeding only in corners, and began to feed in open spaces. The number of feeding loci and the number of bouts of feeding increased under HP treatment.

One possible explanation for the increase in the number of feeding loci is that the rats were hypokinetic, and began to feed near the loci where the pellets were initially located. However, this possibility cannot fully explain the increases observed. Many rats had more feeding loci than there were pellets, which means that some pellets were fed upon at more than one locus. The observer noted that 1 rat, after $0.4 \mathrm{mg} / \mathrm{kg} \mathrm{HP}$, fed upon the same pellet at five different loci. This frequent movement from locus to locus might help to explain the lack of significant suppression of gross locomotion.

HP suppressed food intake in Experiment 2 but not in Experiment 1. This result was not surprising in view of the fact that the amount of food to be consumed in Experiment 1 was very low $(60 \times 45 \mathrm{mg}=2.7 \mathrm{~g})$. In ad- 

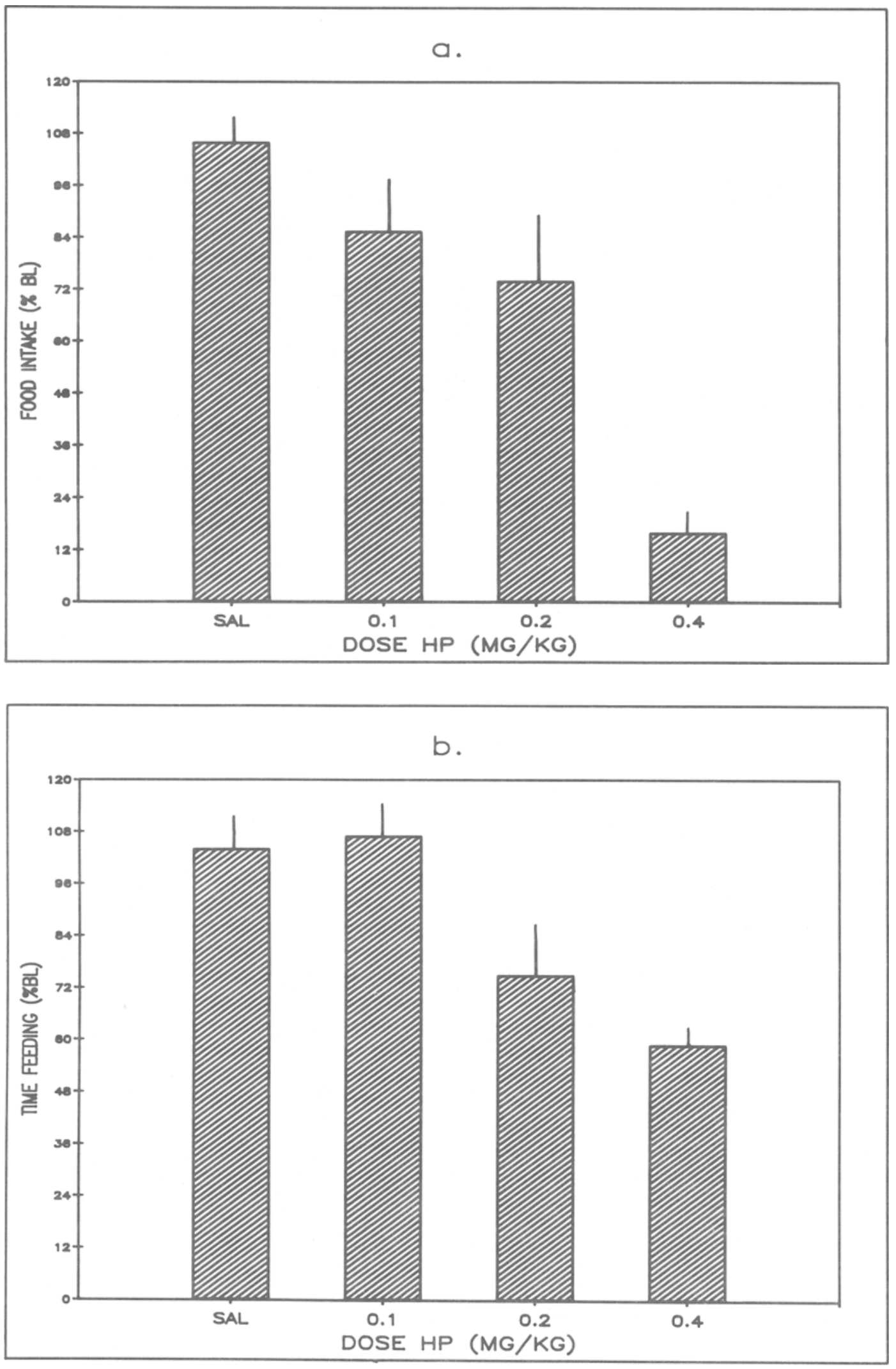

Figure 5. (a) Mean (+SEM) food intake (as percent of baseline) for all treatment conditions (b) Mean (+SEM) time spent feeding (as percent of baseline) for all treatment conditions. 
Table 1

Effects of Haloperidol (HP) on Aspects of Foraging Performance

\begin{tabular}{|c|c|c|c|c|c|c|c|c|}
\hline \multirow[b]{3}{*}{ Behavioral Measure } & \multicolumn{8}{|c|}{ Treatment (mg/kg HP) } \\
\hline & \multicolumn{2}{|c|}{ Saline } & \multicolumn{2}{|c|}{0.1} & \multicolumn{2}{|c|}{0.2} & \multicolumn{2}{|c|}{0.4} \\
\hline & $M$ & $S E M$ & $M$ & $S E M$ & $M$ & $S E M$ & $M$ & $S E M$ \\
\hline Middle approach ( $\%$ bl) & 93.2 & 8.9 & 76.5 & 21.0 & 70.1 & 8.7 & 54.9 & 5.6 \\
\hline Platform approach $(\% \mathrm{bl})$ & 84.3 & 16.7 & 98.2 & 10.6 & 89.3 & 14.3 & 52.4 & 11.0 \\
\hline Platform climbs & 102.0 & 6.9 & 95.4 & 12.5 & 92.1 & 10.6 & 60.6 & 9.6 \\
\hline Number of feeding bouts & 6.5 & 0.2 & 7.8 & 2.0 & 17.2 & 2.7 & 14.7 & 1.8 \\
\hline Partially eaten pellets & 0.0 & 0.0 & 0.8 & 0.8 & 1.3 & 0.5 & 4.2 & 0.6 \\
\hline Number of feeding loci $(\% \mathrm{bl})$ & 107.1 & 9.2 & 133.5 & 15.7 & 207.9 & 29.3 & 211.0 & 25.1 \\
\hline Latency to leave home cage (sec) & 4.8 & 1.5 & 5.7 & 1.8 & 6.0 & 1.9 & 5.5 & 1.5 \\
\hline Latency to first pick up (sec) & 16.1 & 1.5 & 16.8 & 2.8 & 19.0 & 3.6 & 21.3 & 4.1 \\
\hline
\end{tabular}

dition, the food preparations used and the response required to consume the food were quite different in the two experiments. Rats can consume a single $45-\mathrm{mg}$ pellet by lapping it with the tongue; in Experiment 1, rats were required to do so only once every $30 \mathrm{sec}$. The $1.5 \mathrm{-g}$ pellets used in the foraging experiments were large, hard, dry pellets, and consumption of several of these pellets required a considerable amount of effort.

At $0.4 \mathrm{mg} / \mathrm{kg} \mathrm{HP}$, some rats were observed to exhibit an abnormal food-consumption response. Normally, rats feed upon relatively large, dry pellets by holding the pellets with their forepaws. Some of the rats under the high dose of HP attempted to feed upon the pellets without using the forepaws. This observation suggests that some aspect of forepaw control was impaired by HP administration.

HP did not significantly increase latencies to leave the home cage or pick up the first pellet. The effect of DA antagonists on the initial latencies of approach behaviors can depend greatly on the particular task being studied. In a recent report, Blackburn, Phillips, and Fibiger (1987) observed that moderate doses of pimozide significantly increased the initial latency to approach a food hopper after onset of a conditional stimulus. However, several other reports have indicated that initial response latencies or rates can be normal or near normal in rats treated with DA antagonists (see Wise, 1982; Wise, Spindler, DeWitt, \& Gerber, 1978; Wise, Spindler, \& Legault, 1978).

\section{GENERAL DISCUSSION}

Administration of the DA antagonist HP disrupted the normal performance of food-related activities in both Experiments 1 and 2 . The prevailing trend in the literature would be to explain these deficits in terms of a "reward" effect, a "motor" effect, or some combination of the two types of deficits. In my opinion, neither hypothesis in its extreme is the best way to account for the pattern of deficits observed.

Not all aspects of food reward were disrupted by HP, because the rats under HP continued to direct behavior toward food acquisition despite the deficits observed. HPtreated rats in the food-induced activity study consumed all the food pellets presented, and the individual subject that was directly observed continued to stay in proximity to the food dish, a pattern different from that observed during extinction. In a study that used the same activity chamber as that used for Experiment 1 above, Salamone (1986) showed that, although $0.4 \mathrm{mg} / \mathrm{kg}$ HP reduced locomotor activity, this dose did not disrupt the operant of simply being in proximity to the food dish on an FI 30sec schedule. The animals in the foraging study continued to approach food pellets, pick them up, move them from locus to locus, and briefly feed upon the pellets, although the consummatory response was not maintained.

A deficit in the initiation of movement cannot easily explain many of the results of Experiments 1 and 2. Locomotor activity in HP-treated rats in Experiment 1 was higher in the beginning of the session than at the end, a pattern inconsistent with a deficit in the initiation of movement (see also Wise, 1982). Latencies to leave the home cage and to pick up the food pellets in Experiment 2 were unaffected by HP. A deficit in the initiation of movement could not explain the fragmented pattern of feeding in this foraging study, in which the rats treated with HP actually initiated more feeding bouts than normal. The whole pattern of behavior displayed by HP-treated rats in Experiment 2 is different from what could be expected if the effect of HP was simply to suppress movement.

The hypothesis that HP interferes with functions that are common to motor and motivational processes could offer an opportunity to escape from the strict dichotomy between reward and motor hypotheses. Note that the term "motivation" represents a construct that is meant to apply to a number of characteristics of behavior, and that all aspects of motivated behavior are not equally impaired by DA antagonists. In trying to devise a conceptual scheme for the interpretation of DA antagonist effects, it is important to consider the distinction between the directional and activational aspects of motivation (Cofer, 1972; Duffy, 1963). The directional aspect of motivated behavior refers to the selection of a particular response that is directed toward or away from a particular stimulus. In contrast, the activation of a motivated response is a reference to quantitative features of the behavior (e.g., the "vigor," amplitude, rate, or maintenance) that are demonstrated in the execution of that response. According to this model, relatively low doses of DA antagonists 

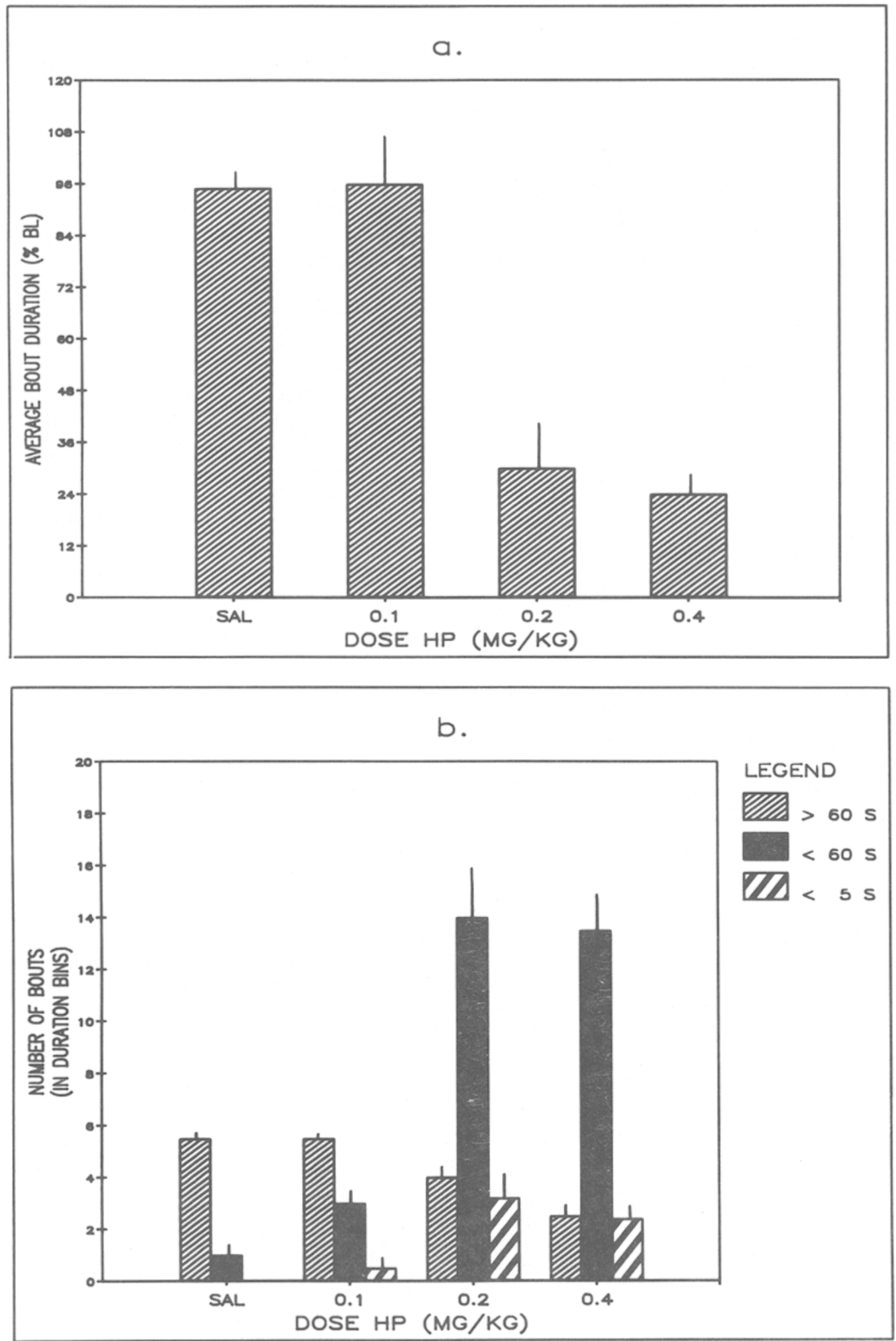

Figure 6. (a) Mean ( $+S E M$ ) duration of the average feeding bout (as percent of baseline). (b) Mean (+SEM) number of bouts that were $>60 \mathrm{sec}$ and those that were 5-60 sec long. Also shown is the number of brief feeding periods not long enough to be considered a feeding bout $(<5 \mathrm{sec})$. 
selectively impair the quantitative features of behavior that are characteristic of response activation, but leave intact the ability to direct behavior in relation to an appetitive or aversive stimulus and to select an appropriate approach or avoidance behavior. This interpretation is consistent with previous experiments in which moderate doses of DA antagonists impaired response speed or rate but not response choice (Bowers, Hamilton, Zacharko, \& Anisman, 1985; Evenden \& Robbins, 1983a; Tombaugh, Szostak, \& Mills, 1983). The present model represents, in motivational terms, what was previously described as the dissociation between response output regulation and response selection mechanisms (Salamone, 1987).

It is proposed that moderate or low doses of HP affect aspects of motor control that are involved in activational aspects of motivation. The effects of a variety of stimuli, including food, water, and sensory stimuli not traditionally considered to be motivationally relevant, converge on a common brain mechanism that exerts influence over a number of motor activities. DA, probably in striatum and nucleus accumbens, is critically involved in this common mechanism, which forms an essential link between motor and motivational processes (see also Mogenson, Jones, \& Yim, 1980; Nauta \& Domesick, 1978). The deficit produced by moderate DA antagonism would have some of the characteristics of both a motor and a motivational deficit. This deficit, however, would be different from that produced by a selective disruption of mechanisms that directly control muscle output, and different from manipulations that would affect all aspects of motivation, including response choice.

HP reduced the sustained motor activity that was induced by food presentation in Experiment 1, and led to a temporal fragmentation of the feeding response in Experiment 2, with increases in the number of bouts of feeding and decreases in average bout duration. These impairments could be related to a deficit in the ability of HP-treated animals to sustain motivated behavior in time. Young (1961) suggested that the ability to maintain responding is a cardinal feature of motivated behavior. Salamone (1987) proposed that the duration of periods of responding should be considered as a significant dimension of behavioral control. Other researchers have also suggested that DA antagonism or lesions can interfere with the temporal maintenance of appetitive and aversive behavior (Anisman, Remington, \& Sklar, 1979; Anisman \& Zacharko, 1982; Gaddy \& Neill, 1977; Sanger, 1986).

In a complex environment such as the foraging room used in Experiment 2, an animal that cannot sustain feeding behavior has a number of alternative behaviors in which to engage. If a rat under HP is capable of performing such brief responses as approaches to food and initiation of feeding or brief periods of locomotion, it is possible that the behavior of the rat would become reorganized and take on the fragmented pattern shown in Experiment 2 . Indeed, if the rat's behavior is still directed toward food acquisition and consumption but the rat is unable to sustain long periods of feeding, it is not unexpected that the rat would repeatedly approach food and initiate feeding, quickly terminate the feeding bout, and then approach the food again.

Kelley and Stinus (1985) reported that 6-hydroxydopamine lesions of the mesolimbic DA system disrupted hoarding behavior in ways that resemble the effects of HP reported here, including feeding in novel places and leaving partially eaten pellets. To explain some of these effects, Kelley and Stinus (1985) suggested that DA in mesolimbic terminal areas mediates hoarding in a nonspecific manner, by generating a high level of arousal, facilitating certain responses, and maintaining the behavior. DA has also been implicated in the regulation of transitions between behaviors by influencing response switching and perseveration (Evenden \& Robbins, 1983b) and response sequencing (Cools, 1980). Thus, there is substantial evidence that DA is involved in the arousal, maintenance, and patterning of motivated behavior that is observed in instrumental conditioning procedures or under seminaturalistic conditions.

The position that DA antagonists impair aspects of behavior that reflect response activation is compatible with the view of Wise $(1982,1985)$ that these drugs impair "motivational arousal." This view, however, need not be seen as inconsistent with the motor functions often assigned to DA systems. Rather, it is a recognition that motor functions that are very sensitive to disruption with DA antagonists are involved in the control of features of behavior that are fundamental to the concept of motivation.

\section{REFERENCES}

AhLENiUS, S. (1979). An analysis of behavioral effects produced by drug-induced changes in dopaminergic neurotransmission in the brain. Scandinavian Journal of Psychology, 20, 59-64.

anisman, H., Remington, G., \& SkLar, L. S. (1979). Effect of inescapable shock on subsequent escape performance: Catecholaminergic and cholinergic mediation of response initiation and maintenance. Psychopharmacology, 61, 107-124.

Anisman, H., ZACHARKo, R. (1982). Stimulus change influences escape performance: Deficits induced by uncontrollable stress by haloperidol. Pharmacology, Biochemistry \& Behavior, 17, 263-269.

Blackburn, J. R., Phillips, A. G., \& Fibiger, H. C. (1987). Dopamine and preparatory behavior: I. Effects of Pimozide. Behavioral Neuroscience, 101, 352-360.

Bowers, W., Hamilton, M., Zacharko, R. M., anisman, H. (1985). Differential effects of pimozide on response-rate and choice accuracy in a self-stimulation paradigm in mice. Pharmacology, Biochemistry \& Behavior, 22, 521-526.

Broekkamp, C. L., Van Dangen, P. A., \& Van Rossum, J. M. (1977). Neostriatal involvement in reinforcement and motivation. In A. R. Cools, A. M. Lohman, \& J. H. van den Berken (Eds.), Psychobiol. ogy of the striatum (pp. 61-72). Amsterdam: Elsevier North-Holland. Church, W. H., Justice, J. B., Neill, D. B. (1987). Detecting behaviorally relevant changes in extracellular dopamine with microdialysis. Brain Research, 412, 397-399.

COFER, C. N. (1972). Motivation and emotion. Glenview, IL: Scott, Foresman.

Cooss, A. R. (1980). Role of neostriatal dopaminergic activity in sequencing and selecting behavioral strategies: Facilitation of processes involved in selecting the best strategy in a stressful situation. Behavioural Brain Research, 1, 361-378.

DufFY, E. (1963). Activation and behavior. New York: Wiley. 
Evenden, J. L., Robins, T. W. (1983a). Dissociable effects of damphetamine, chlordiazepoxide and alpha-flupenthixol on choice and rate measures of reinforcement in the rat. Psychopharmacology, 79, $180-186$.

EVENDEN, J. L., RoBbins, T. W. (1983b). Increased response switching, perseveration, and perseverative switching following damphetamine in the rat. Psychopharmacology, 80, 67-73.

Fibiger, H. C., CARTer, D. A., \& Philuts, A. G. (1976). Decreased intracranial self-stimulation after neuroleptics or 6-hydroxydopamine: Evidence for mediation by motor deficits rather than by reduced reward. Psychopharmacology, 47, 21-27.

GAdDY, J. R., NEILL, D. B. (1977). Differential behavioral changes following intrastriatal application of 6-hydroxydopamine. Brain Research, 119, 439-446.

GRAY, T., * WISE, R. A.(1980). Effects of pimozide on lever-pressing behavior maintained on an intermittent reinforcement schedule. Pharmacology, Biochemistry \& Behavior, 12, 931-935.

HoRNYKIEWICZ, O. (1972). Dopamine and its physiological significance in brain function. In G. H. Browne (Ed.), The structure and function of nervous tissue (pp. 367-415). New York: Academic Press.

Janssen, P. A., Niemegeers, C. J. F., \& Schellekens, K. H. L. (1965). Is it possible to predict the clinical effects of neuroleptic drugs (major tranquilizers) from animal data? Arzneimittel-Forschung, 15, $104-117$

Keehn, J. D., Coulson, G. E., Kueb, J. (1976). Effects of haloperidol on schedule-induced polydipsia. Journal of the Experimental Analysis of Behavior, 25, 105-112.

KeEHN, J. D., RiUSECH, R. (1977). Schedule-induced water and saccharin polydipsia under haloperidol. Bulletin of the Psychonomic Society, 9, 413-415.

Kelley, A. E., Strnus, L. (1985). Disappearance of hoarding behavior after 6-hydroxydopamine lesions of the mesolimbic dopamine neurons and its reinstatement with L-DOPA. Behavioral Neuroscience, 99. 531-545.

Killeen, P. (1975). On the temporal control of behavior. Psychological Review, 82, 89-115.

KILLEEN, P. (1981). Incentive theory. In D. Bernstein (Ed.), Response structure and organization (pp. 169-216). Lincoln: University of Nebraska Press.

Marshall, J. F., Richardson, J. S., * Teitelbaum, P. (1974). Nigrostriatal damage and the lateral hypothalamic syndrome. Journal of Comparative \& Physiological Psychology, 87, 808-830.

Mocenson, G. J., Jones, D. L., \& YIM, C. Y. (1980). From motivation to action: Functional interface between the limbic system and the motor system. Progress in Neurobiology, 14, 69-97.

NAutA, W. J., Domesick, V. B. (1978). Crossroads of limbic and striatal circuitry: Hypothalamo-nigral connections. In K. E. Livingston \& O. Hornykiewicz (Eds.), Limbic mechanisms (pp. 75-93). London: Plenum Press.
Robbins, T. W., Koos, G. F. (1980). Selective disruption of displacement behavior by lesions of the mesolimbic dopamine system. Nature, 285, 409-412.

Rolls, E. T., Rolls, B. J., Kelly, P. H., Shaw, S. G., Wood, R. J., \&ALE, R. (1974). The relative attenuation of self-stimulation, eating and drinking produced by dopamine-receptor blockade. Psychopharmacology, 38, 219-230.

Salamone, J. D. (1986). Different effects of haloperidol and extinction on instrumental behaviors. Pschopharmacology, 88, 18-23.

SAlAmone, J. D. (1987). The actions of neuroleptic drugs on appetitive instrumental behaviors. In L. L. Iversen, S. D. Iversen, \& S. H Snyder (Eds.), Handbook of psychopharmacology (pp. 575-608). New York: Plenum

Salamone, J. D., Abercrombie, E. A., Keller, R. W., Zigmond, M. J., \& STrucker, E. M. (1987). Pharmacological and behavioral stimulation produce changes in striatal dopamine activity measured by in vivo dialysis. Society for Neuroscience Abstracts, 13, 832.

SANGER, D. J. (1986). Response decrement patterns after neuroleptic and non-neuroleptic drugs. Psychopharmacology, 89, 98-104.

STRICKER, E. M., ZiGmond, M. J. (1976). Recovery of function after damage to central catecholamine-containing neurons: A neurochemical model for the lateral hypothalamic syndrome. In J. M. Sprague \& A. N. Epstein (Eds.), Progress in psychobiology and physiological psychology (pp. 121-188). New York: Academic Press.

Tombaugh, T. N., Szostak, C., Mills, P. (1983). Failure of pimozide to disrupt acquisition of light-dark and spatial discrimination problems. Psychopharmacology, 79, 161-168.

UNGERSTEDT, U. (1971). Adipsia and aphagia after 6-hydroxydopamineinduced degeneration of the nigro-striatal dopamine system. Acta Physiologica Scandinavica, 83(Suppl. 367), 95-122.

Wallace, M., Singer, J., Finlay, J., \& Gibson, S. (1983). The effect of 6-OHDA lesions of the nucleus accumbens septum on scheduleinduced drinking, wheelrunning and corticosterone levels in the rat. Pharmacology, Biochemistry \& Behavior, 18, 129-136.

WISE, R. A. (1982). Neuroleptics and operant behavior: The anhedonia hypothesis. Behavioral \& Brain Sciences, 5, 39-87.

WISE, R. A. (1985). The anhedonia hypothesis: Mark III. Behavioral \& Brain Sciences, 8, 178-184.

Wise, R. A., Spindler, J., DeWitt, H., \& Gerber, G. J. (1978). Neuroleptic-induced "anhedonia" in rats: Pimozide blocks reward quality of food. Science, 201, 262-264.

Wise, R. A., SPINDler, J., \& Legault, L. (1978). Major attenuation of food reward with performance-sparing doses of pimozide in the rat. Canadian Joumal of Psychology, 32, 77-85

Young, P. T. (1961). Motivation and emotion. New York: Wiley.

(Manuscript received February 10, 1988; revision accepted for publication May 24, 1988.) 